\title{
NATO AND EVIDENCE-BASED MILITARY AND DISASTER MEDICINE: CASE FOR VIGOROUS WARRIOR LIVE EXERCISE SERIES
}

\author{
John M. Quinn'1, Vladimír Bencko ${ }^{1}$, Alexander V. Bongartz², Preslava Stoeva ${ }^{3}$, Adrijana Atanasoska Arsov ${ }^{4}$, \\ Stefano De Porzi ${ }^{5}$, Milos Bohonek ${ }^{6,12}$, Ronald Ti', Jack Taylor ${ }^{5}$, John Mitchell ${ }^{8}$, Veronika Reinhard ${ }^{9}$, \\ Petr Majovsky ${ }^{10}$, Jozef Kuca ${ }^{5}$, Petr Kral ${ }^{5}$, Laszlo Fazekas ${ }^{5}$, Zoltan Bubenik ${ }^{10,11}$ \\ ${ }^{1}$ Prague Centre for Global Health, Institute of Hygiene and Epidemiology, First Faculty of Medicine, Charles University, Prague, Czech Republic \\ ${ }^{2}$ Emergency Medical Faculty, Prague Institute of Postgraduate Medical Education, Prague, Czech Republic \\ ${ }^{3}$ Department of Global Health and Development, London School of Hygiene and Tropical Medicine, London, United Kingdom \\ ${ }^{4}$ Medical Military Centre Skopje, Army of the Republic of North Macedonia, Skopje, Republic of North Macedonia \\ ${ }^{5}$ Interoperability Branch, NATO Centre of Excellence for Military Medicine, Budapest, Hungary \\ ${ }^{6}$ Department of Haematology and Blood Transfusion, Military University Hospital, Prague, Czech Republic \\ ${ }^{7}$ Specialist Technical Advisor, Poland Office, Department of Defence, Canberra, Australia \\ ${ }^{8}$ Secretary of Defence, Operational Medicine Readiness Policy and Oversight, Pentagon, Washington, D.C., USA \\ ${ }^{9}$ Estonian Military Academy, Tartu University Hospital, Tartu, Estonia \\ ${ }^{10}$ Ministry of Defence of the Czech Republic, Prague, Czech Republic \\ ${ }^{11}$ Committee of Chiefs of Military Medical Services in NATO, Brussels, Belgium \\ ${ }^{12}$ Faculty of Biomedical Engineering, Czech Technical University in Prague, Prague, Czech Republic
}

\section{SUMMARY}

The North Atlantic Treaty Organization (NATO) is the premier and only security alliance uniting 30 countries and growing with many partner states in the provision of collective security and against threats posed by conflict and natural disasters. Security of countries and communities is increasingly threatened by a broad spectrum of unconventional types of war and disease threats - from hybrid and asymmetric to multi-domain and peer-to-peer/near-peer conflict. The NATO Centre of Excellence for Military Medicine (MILMED COE) is the centre of gravity for medical best practices and promotion of medical doctrine across the NATO alliance. Disaster medicine is multidisciplinary and in NATO, multinational, requiring best practices that are driven by data and evidence to prevent death on the battlefield and prepare for future conflicts. "Vigorous Warrior" is a live military and disaster medicine exercise series using both civilian and military actors across all sectors of health focused on health security and identifying lessons learned to ready the alliance for future threats. In this brief report, we make the case that the Vigorous Warrior exercise exposes gaps, highlights challenges and generates an evidence base to make NATO military medicine systems more robust, more efficient and in provision of best medical practices. We specifically argue that clinical data capture must be duplicated and continuous across the alliance to ensure evidence-based medicine stays current in NATO military medical doctrine.

Key words: military medicine, disaster medicine, NATO

Address for correspondence: J. Quinn, Prague Centre for Global Health, Institute of Hygiene and Epidemiology, First Faculty of Medicine, Charles University, Studničkova 7, Prague, Czech Republic. E-mail: john.quinn@lf1.cuni.cz

https://doi.org/10.21101/cejph.a6045

\section{INTRODUCTION}

\section{The Event}

Military and disaster medicine are seated inside the broad discipline of prehospital medicine. During times of disaster and pandemic response, the requirement of military and civilian interoperability must be practiced and continuously reviewed. This inherently multidisciplinary clinical approach to patient care in resource-poor, sometimes dangerous, austere, and challenging environments requires specific evidenced-based approaches, clinical treatment protocols and guidelines that collectively help deliver best practices. This requires both clinical medicine and public health best practices. These best practices must be based on evidence, be continuously reviewed and tested in live exercises for the civilian-military health interface and be vigorously challenged. The Vigorous Warrior (VW) medical exercise series is conducted biennially, with five successful iterations since 2011. These exercises include medical actors from the North Atlantic Treaty Organization NATO, NATO partners nations, military and civilian 
disaster responders, search and rescue (SAR) teams and myriad other health partners devoted to disaster and pandemic response.

In general, the medical exercises are designed to enhance NATO's capabilities and ensure that NATO's medical concepts, equipment and interoperability are drilled and tested across the full capability requirement spectrum in the event of a NATO Article 5 scenario or sub-threshold security event. The primary aims of these exercises are to provide NATO and partner nations a multipurpose platform to collectively train their medical forces and personnel for disaster and pandemics; test and experiment new concepts and medical doctrine; medically evaluate national and multinational medical treatment facilities in accordance with NATO doctrine; produce medical lessons identified and lessons learned (LL); and provide participants with multinational experience to enhance the provision of public health and health care for NATO operations (1).

The tangible outcome from the Vigorous Warrior series directly strengthens partnerships at the military to military (M2M) and civilian-military interface (Civ-Mil), improves medical interoperability, and demonstrates the Alliance's commitment to improving international military medical collaboration to prevent death on the battlefield and in disaster (1). More than 2,600 medical and ancillary personnel from 39 NATO and partner nations successfully conducted the joint, multilevel, multinational Vigorous Warrior 2019 (VW'19) medical exercise in Romania from April $1 \mathrm{st}-14$ th, 2019 .

\section{Leadership of VW'19 - NATO Centre of Excellence for Military Medicine, COMEDS and Lessons Learned Process}

Rooted in the NATO medical military doctrine are the "Principles and Policies of Medical Support" (MC 326-3) which are being challenged in the changing global security environment, and specifically by the increasing threat of hybrid war (2). This dictates that the public, NATO and NATO partner nations expectations of high-quality medical support is increasing while risks are growing across all sectors $(3,4)$. Military healthcare is a patient-centric health service provision by military healthcare professionals for the defined populations at risk; it encompasses preventive health protection, prehospital emergency care, primary healthcare, hospital care and rehabilitative care; military healthcare incorporates the full range of military operations including humanitarian assistance (5).

The highest medical decision-making body in NATO, the Committee of the Chiefs of Military Medical Services (COMEDS), supported the establishment of the NATO Centre of Excellence for Military Medicine (MILMED COE) to coordinate efforts to advance military medicine across the alliance. Hungary as the framework nation, along with the sponsoring nations have created MILMED COE which remains the marquee venue for academics, researchers, warfighters, command staff, and all voices in support of medical best practices to exchange ideas and incubate medical innovation and lessons learned to save life on the battlefield (6).

The purpose of the NATO medical standard is to offer guidance to physicians and other healthcare providers. Single nations will have their own standards of care, but NATO standards are designed to promote standardization and interoperability for NATO operations across the alliance $(7,8)$. The requirement for
MILMED COE to prepare for future military medical support is acute and requires continuous medical debate and rigorous review and continuous update of NATO medical doctrine in order to save lives. Unanticipated risk and consequences from hybrid warfare make this growing threat to health and health security more complex in a near-peer and peer-to-peer threat environment.

The North Atlantic Council accredited and activated the NATO MILMED COE in Budapest in 2009. The MILMED COE has ushered in a Lessons Learned (LL) process where Subject Matter Experts (SMEs) can share the clinical and medical command across disciplines to help mitigate mortality and morbidity from war and disaster where NATO forces respond and deploy. The Concept Development and Experimentation (CD\&E) seated in the MILMED COE conducts experiments on civil military collaboration throughout VW and the observations and LL are shared to enhance practice. MILMED COE is driving the way to prepare NATO with the best tools for medical best practices and processes with evidence-based medical practices.

\section{Basic Definitions}

\section{Evidence-based Medicine}

Evidence-based medicine (EBM) is the care of patients using the best available research evidence to guide clinical decision making; the focus is upon applying the results of research involving patients and clinical outcomes, such as mortality, morbidity, symptomatology, and loss of function $(9,10)$. Pragmatic solutions in disaster response, war and warfighting for medical standards are challenging. MILMED COE deploys EBM to identify mixedstrength research results and levels-of-evidence, enabling practitioners to quickly form clinical guidance and recommendations that constitute NATO military medical doctrine. VW offers a venue for all alliance and partners to share their clinical practice and experience in a training environment.

\section{Health and Security}

Definitions of global health security are hotly debated and still under review in the operational and academic sectors (11-15). Global health security is defined as the activities required to minimize the danger and impact of acute public health events that endanger the collective health of populations and communities across geographical regions and boundaries (12). Definitions, however, broadly focus on preventing infectious diseases originating in or affecting the Global South from spreading to the Global North or further across the South (16). Such a view of global health security is very narrow and limiting. An expanded concept of health security is needed to include epidemiological considerations such as the shift from expert knowledge to algorithmic decision making for health security threats, the securitization of global health, pandemics and the expansion of hybrid threats impacting health (16) as well as the challenges affecting populations caught up in non-traditional conflict, e.g., TT non-international armed conflict, hybrid and asymmetric war. Insight from VW can support NATO operations and mitigate mortality and morbidity on the battlefield, including all combatants and civilians. This needs to be expanded to noncommunicable and chronic disease for deployed personnel into a theatre of operations, and also in quantifying the health risk on individual and disease characteristics (17). 


\section{NATO Military Medical Doctrine}

The NATO military medical doctrine is the organization, preparation, prevention, execution, and medical support of military operations updated through evidence based doctrine and offered to allied, multinational and coalition forces (18). The doctrine, intended for NATO forces, is malleable and can be shared with participating partner nations for war and disaster operations under a coalition of NATO and non-NATO nations through a Combined Joint Task Force (CJTF) (19). Thus, no distinctions are drawn within the document between solely NATO operations, non-Article 5 Crisis Response Operations (CRO) by Allied forces and CJTF operations (20). NATO medicine provides civilian medicine best practices and the lessons learned process provides a feedback loop for information sharing that offers public health for NATO states, and the world at large.

\section{Roles/Echelons of Care}

The NATO Military doctrine supports an integrated health services support system to triage, treat, evacuate, and rehabilitate the wounded efficiently, which begins with the warfighter on the battlefield and ends in tertiary and definitive care facilities (21). This care begins with first aid (self-aid/buddy aid, and combat lifesaver) which includes tactical combat casualty care (TCCC), and prolonged field care (PFC), and rapidly progresses through a spectrum of damage control resuscitation (DCR) and damage control surgery (DCS). Different roles denote differences in capability, and at each level of capability warfighters are treated and return to duty or are prepared and packaged for evacuation with medical care administered while en route to a higher role/level (22). VW'19 focused on medical activities across all levels and roles of care from point of injury to Role 4 . Level/Role 1 provides immediate first aid delivered at the point of injury with application of principles remote damage control resuscitation (RDCR). Per NATO doctrine, Role 2 must be $100 \%$ mobile and is divided between "forward", "basic" and "enhanced" (R2B/R2E). Roles $2 \mathrm{~F}$ are highly mobile and deployable enabling forward projected resuscitative and surgical treatment to control bleeding, maintain circulation, restore perfusion and preserve life, limb, and function. Roles 2B and Roles 2E offer an increased medical capability and limited inpatient bed space and provide DCR and DCS, basic primary care, occasionally optometry, combat operational stress control and mental health, dental support, variable laboratory, and X-ray capability. Each NATO state and partner nation may offer a slightly different capability at the R2B/R2E medical treatment facilities (MTFs).

Level/Role 3 represents the highest level of medical care available within the combat or disaster zone with the bulk of inpatient beds and expanded surgical and diagnostic capability. In VW'19, one Romanian Role 3 was deployed with multinational staff and offered advanced surgical capabilities augmented by multiple nations and medical specialties. Strategic medical evacuation (STRATEVAC) was also simulated to patients' countries of origin to Role 4 during VW'19. Role 4 provides definitive medical care and rehabilitation.

\section{Collective Self-Defence}

Collective self-defence means that an attack against one ally is considered as an attack against all allies of the NATO Alliance (23). The principle of collective self-defence is enshrined in
Article 5 of the Washington Treaty and relies on deterrence, or primary prevention to the threat of attack or invasion in any battle domain. The preparation for a sub-threshold Article 5 event, perhaps without enemy attribution and not meeting the requirements for a full-blown Article 5 enaction, is an increasing risk through hybrid warfare and open activities by aggressor states.

Primary prevention is defined as those actions that first of all prevent a security crisis from taking place. Since Russia's illegal annexation of Crimea in 2014 and the rise of security challenges from the south, including Islamic State in Iraq and the Levant (ISIL)/Islamic State in Iraq and Syria (ISIS), and other terrorist groups across several continents, NATO has implemented the biggest increase in collective defence activities since the Cold War (25). Some measures implemented include Joint Intelligence, Surveillance and Reconnaissance (JISR) and more recently at the Warsaw Summit in July 2016, Allies also recognized cyber defence as a new operational domain, to enable better protection of networks, missions and operations $(24,25)$. The purpose of VW'19 is to best support medically all NATO anticipated security operations and mitigate death and morbidity in medical disasters in support of public health. VW is a series that can test medical systems when multi-domain battle activities are occurring concurrently.

\section{Multi-domain Battle and Warfare}

Operationally, multi-domain battle (MDB) allows defence forces to outmanoeuvre adversaries physically and cognitively, applying combined arms in and across all domains (i.e., land, space, air, sea, and cyber); it provides a flexible means to present multiple dilemmas to an enemy and create temporary windows of localized control to seize, retain and exploit the initiative $(26,27)$. Medically, multi-domain battle and warfare (MDW) is the future and NATO must navigate and thrive in this multi-threat environment for all future operations. Any Article 5 or sub-threshold event will require joint commitments from NATO states and this 'jointness' for medical operations, force health protection to medical evacuations will requires interoperability (28).

\section{Asymmetric and Hybrid Warfare}

Asymmetric warfare can be simply described as conflict between opposing forces (two or more) which may differ greatly in military power and capabilities. Conventional logic dictates that such conflicts should not happen (29). As a result of the significant discrepancies in capability between opponents, such conflicts typically involve the use of unconventional operations and tactics, but also tend to spill beyond conventional actors to affect civilian populations (30). Such warfare is usually between a larger power and smaller force and may reside within one state or across many in semi-autonomous regions or ungoverned spaces in fragile and failed states.

While there are many definitions of hybrid warfare (31), the term is simply defined as a military strategy in which conventional warfare is integrated or mixed with unconventional warfare or covert tactics, countermeasures and unconventional operations across domains of battle (i.e., land, sea, air, space, cyber, etc.) (32). The term "hybrid warfare" is credited to Nemeth (33), who used it in reference to the conflict in Chechnya. Prior to 2014, the term was most frequently used to describe the strategy used by the Hezbollah in the 2006 Lebanon War (31). Subsequently, 
Russia's hostile actions in Ukraine and the violence perpetrated by the Islamic State of Iraq and the Levant (ISIL) have also been designated as examples of hybrid war (34). A potential adversary, Russia, deployed hybrid warfare globally with the main characteristics of economizing force or minimizing traditional military presence.

Hybrid warfare is also characterized by "the aim of creating ambiguity and confusion on the nature, the origin and the objective of the threat; the ability to identify and exploit the vulnerabilities of the targets; the capacity to keep the level of hostility below the threshold of conventional war" (34). Hybrid warfare is persistent in breaking down the traditional binary delineation between war and peace through a dynamic intensity of conflict; and is population-centric (35). The term "hybrid" has dominated much of the discussion about modern and future warfare (36). One key concern of relevance here is that "modern weapon systems have greatly increased the lethality of non-state actors" (31). Medical operations, therefore, are greatly hindered by these lethal concepts of warfare and pose specific challenges to the treatment, transportation and prevention of death for all medical operations. NATO must design strategies on how to operate within these areas of warfare and provide clinical best practices in a thorough dynamic environment.

\section{Medical Innovation and Emerging Technologies}

One key feature of the VW series is the ability to test new medical ideas and equipment and to experiment with new process and protocols where M2M and Civ-Mil may have gaps. The sections below describe some of the highlights from the VW'19 related to medical innovation, emerging trends in military medicine and prehospital medical provision.

\section{Blood and Blood Products (Class 8B) Logistics}

VW 19 - the first time a medical logistics tabletop exercise (MEDLOG TTX) was specifically planned and executed. The task was to create a tabletop exercise (TTX) that demonstrated the limitations of blood and blood products (class 8B logistics) the Article $\mathrm{V}$ battlefield. The eventual product was a time based war game whose participants consisted of four R2B deploying to EX VW 19.

The main aims of the TTX were to demonstrate to the participants that there would be several major restraints/constraints operating in this particular battlespace. The four most likely article 5 tactical situations affecting class $8 \mathrm{~B}$ logistics were considered to be: limited movement from R1 to R2 and vice versa; limited rearwards movement from R2 to R3; limited to no air movement in the tactical battlespace; and limitations of emergency donor pools on the battlefield.

As class 8B items of supply (blood and blood products) are thermolabile items, it was important to introduce a time-space construct to this TTX. The results of the MEDLOG TTX were validated by both pre- and post-surveys as well as detailed one on one debriefs. The MEDLOG TTX achieved its primary aim of making participants more aware of the restrictive nature of the Article V battlefield.

\section{Blood and Blood Products}

VW'19 was an excellent Petri dish to test the pressing concepts of blood and blood products prepared, transported and adminis- tered at the Role 1 and Role 2 settings. The Trauma Haemostasis and Oxygenation Research (THOR) Network and RDCR provide concepts rooted in evidence-based medicine and that the NATO military medical doctrine must duplicate, replicate and emulate going forward $(37,38)$. The lethal triad in haemorrhagic trauma is hypothermia, acidosis and coagulopathy and rapid access to blood and blood products extremely early and closer to the point of injury may decrease mortality (39). Despite advancements in battlefield medical interventions at point of injury and Role 1, major haemorrhage persists as a major cause of death from warfighting injuries. Transfusion support across the alliance and translation to military prehospital resuscitation and RDCR were challenged and many lessons were learned at VW'19. Integral part of haemostatic resuscitation protocol is using of tranexamic acid (TXA) within 3 hours of injury and NATO forces should include TXA in the treatment of trauma patients with uncontrolled bleeding (40).

Only some allied forces had a declared and active walking blood donor protocol - USA, Canada, Norway, France, and UK. The Estonia team stated they are starting to integrate a legal framework for a walking donor programme, walking blood bank (WBB), also introduced in the Czech Republic. There is an inadequate basic load of blood and blood products. The logistics chain for blood and blood products should be robust, interoperability must address the ability to send Estonian blood to a Romanian hospital - medicolegally - as well be able to tap into the civilian health system without middlemen and establish a cold chain system within hours, not weeks, to facilitate DCR/DCS from 40 units to 120 units. These numbers are anecdotal but are inadequate for an article 5 security event/scenario.

More blood products, a legal framework for instant access to the civilian system and blood, within hours is vital and key for NATO and NATO partner nations in the event of a deployment or hybrid deployment, non-article 5 or sub-threshold article 5 scenario. The use of cryopreserved blood products - red blood cells (RBCs), and platelets (PLT) is also a relevant method in DCR/DCS, where some NATO member states already have implemented into clinical practice. The THOR network leads on best practices and its continuous process should feed into the MILMED COE process in the future.

\section{Diagnostics}

VW'19 was an excellent opportunity to challenge the paradigm of each nation at the Role 2 MTFs and that of clinical diagnostics related to trauma. Unification in practice remains a challenge and the VW series offers a venue for gap identification and NATO process and operational alignment. For example, thoracic, abdominal and pelvic trauma and the capability to conduct the extended focused assessment with ultrasound in trauma (eFAST), point of care (POC) lactate and haemoglobin $(\mathrm{Hb})$ may serve as clinical bellwethers. Bedside or POC lactate via rapid test in trauma helps indicate response to DCR, especially when offered in the form of arterial blood gas (ABG) with multiple other parameters. Bedside and POC Hb can help guide decision making in blood and blood products and response to RDCR, especially in resource poor settings when blood products may be in inadequate supply. Part of the WBB protocol is a rapid test for blood typing, and possibly in the future, tests for transfusion transmissible diseases (hepatitis $\mathrm{B}$ and $\mathrm{C}, \mathrm{HIV}$, malaria, and others). 


\section{Lactate}

Lactate is a product of anaerobic metabolism. In the presence of trauma, it can be used as a marker on demand and availability of oxygen and changes in lactate levels act as a marker in DCR. Most Role 2's deployed at the VW'19 had a commercially purchased iStat portable machine for arterial blood gas (ABG)/venous blood gas (VBG) with lactate, many also had cartridges that test $\mathrm{pH}$, base excess, bicarbonate, partial pressure of oxygen and carbon dioxide, among others. All Role 2's had various amounts of blood test cartridges. One local national facility had lactate tests but by reagent, not a rapid test. Lactate in trauma and response to RDCR helps dictate treatment and having lactate, accurate measurements can help prioritize patient movement in times of resource poor medical evacuation chains and lack of senior clinical support and decision-making (36).

\section{Haemoglobin}

$\mathrm{Hb}$ is on most iStat cartridges as well for a full or complete blood count, one unit deployed at VW'19 used only blood film and reagent, no rapid test. Blood and blood products (including walking donor protocols): all units brought blood and blood products (training purpose bloods), most bought RBCs and plasma. The number/basic load across many ranged from 40 units, 80 units all the way to 120 units.

\section{Extended Focused Assessment with Sonography in Trauma}

Extended focused assessment with sonography in trauma is a rapid POC ultrasound (US) examination that uses minimally invasive ultrasound to screen for pericardial effusion or blood/ fluid in the abdominal cavity and air or blood in the chest in the presence of trauma. All Role 2 MTFs reviewed had access to ultrasound. Some ranged from two units, in the form of Sonosite "laptop" style to larger "breadbox" sized older ultrasound. One unit had the handheld device only, which requires cables and a smartphone with the downloaded application to view. Most units had the curved array probe, some had the linear one. No cardiac probes were observed. Without CT capabilities in the Role 2 paradigm, ultrasound should be flooded in the clinical space.

US broad training across all practitioners (nurses, paramedics, logistics/technicians and of course doctors) must be a mainstay. Portability, battery power and fluency with the eFAST, in addition to other basic procedures (optic nerve for increased cranial pressure, basic or nuanced fractures, cardiac exams, etc.) should be commonplace and integrated into practice across the alliance. Identifying life threatening injuries that can be fixed quickly (i.e. pneumothorax, pericardial effusion, etc.) and are minimally invasive should become common practice in NATO military medical doctrine.

\section{Retrograde Endovascular Balloon Occlusion of Aorta}

Pushing future capabilities and instruments for RDCR/ DCR and DCS is best performed conceptually in a training environment, not open combat. No better place to consider the invasive yet potentially lifesaving intervention of retrograde endovascular balloon occlusion of aorta (REBOA) in aorta and major vessel trauma in the pelvis and abdomen. In the future such prehospital invasive lifesaving procedures such as REBOA should be considered.

\section{The Future}

MILMED COE provides key leadership that dictates evidenced based medicine into the NATO military medicine doctrine. Multiple challenges are growing to provide expert medical care from point of injury to Role 3 and onwards to Role 4. The Vigorous Warrior series is an excellent venue to push limits, test process and procedures and theorize what medical innovation is needed that enhance best practices.

Article 5 and subthreshold article 5 scenarios pose potential challenges in provision of medical care across the alliance in the hybrid and multi-domain environment. The principle of collective defence is at the very heart of NATO's founding treaty and medically all nations must be ready to provide rapid warfighting medical support in the face of war and disaster.

\section{CONCLUSION}

NATO remains the premier security alliance uniting states to ensure collective security and medical best practices. Hybrid, asymmetric and the multi-domain battlefield in the future pose significant challenges in offering clinical best practices for NATO warfighters. The NATO Centre of Excellence for Military Medicine provides leadership in the provision of medical best practices and promotion of medical doctrine across the NATO alliance. "Vigorous Warrior" is a live military and disaster medicine exercise series using both civilian and military actors across all sectors of health focused on health security and identifying lessons learned to ready the alliance for future threats. It is a vital requirement to continuously practice, engage and fine-tune the military and civilian interoperability for disaster response and pandemic relief.

In this brief report, we make the case that the Vigorous Warrior exercise exposes gaps, highlights challenges and generates an evidence base to make NATO military medicine systems more robust, more efficient and in provision of best medical practices. COVID-19 has impacted multiple exercises at NATO. The next Vigorous Warrior live exercise is likely to take part in 2022 as a Tabletop Exercise (TTX) due to the current COVID-19 crisis. This event will not only highlight how important the military-civilian partnership is to public health efforts across Europe and the globe but also how NATO can play a leadership role in preparing for the next pandemic.Clinical data capture must be duplicated and continuous across the alliance to ensure evidence-based medicine stays current in NATO military medical doctrine.

\section{Acknowledgements}

The authors would like to thank MILMED COE for its continuous efforts to apply best medical practices in war and disaster, and in the improvement of clinical process through the Lessons Learned sector. The authors would also like to thank NATO, NATO partner states and support personnel for their duty and service in support of saving life, deterrence of threats, common defence, systems resilience, and overall medical readiness.

\section{Conflicts of Interests}

None declared

\section{Disclosure}

Statements and opinions expressed in the article and all communications herein are those of the authors alone and do not represent the publisher, 
NATO, NATO partner states, any government, institute, academic institution, or affiliated body of any kind. The conclusions and statements in this paper do not in any way dictate or constitute NATO, or any government's policy, past, present or future and are solely the conclusions and comments of the authors alone.

\section{REFERENCES}

1. Fazekas L, McCown ME, Taylor JB, Ferland KA. NATO military medical exercise Vigorous Warrior 2017. J Spec Oper Med. Spring 2019;19(1):2730.

2. Allied Joint Medical Doctrine for Military Health Care (MHC). NATO standard: AJMedP-8(A)(1) [Internet]. Brussels: NATO; 2018 [cited 2020 Mar 28]. Available from: https://www.coemed.org/files/stanags/02 AJMEDP/AJMedP-8 EDA V1 E 2598.pdf

3. Gubás F. Medical support of military operations led by organizations of international crisis management. Sci Mil J. 2015;10(1):25-9.

4. Růžička M, Humlíček V, Witt P. Medical support in asymmetric operations. Mil Med Sci Lett. 2012;81(3):90-5.

5. Ciottone GR, Biddinger PD, Darling RG, Fares S, Keim ME, Molloy MS, et al., editors. Ciottone's disaster medicine. Philadelphia: Elsevier; 2015.

6. Quinn J, Bencko V, Osvald V, Majovsky P, Kral P, Bubenik Z, et al. Conference report: Future Forces Forum Prague, World Medical Congress (CEBIRAM) 2018. Mil Med Sci Lett. 2019;88(1):37-40.

7. Balázs R, Kopcsó I. Evidence based military medicine - The NATO Trauma Registry Initiative. AARMS. 2014;13(1):17-29.

8. Bedubourg G, Wiik H, Queyriaux B, Lausund P, Meynard J. Collection and sharing of medical information and medical intelligence (M2I) in NATO: a transversal survey. J R Army Med Corps. 2018;164(4):271-6.

9. Vitiello A. Evidence based medicine: how to practice and teach EBM, Sackett DL, Straus SE, Richardson WS, Rosenberg W, Haynes RB, 2nd ed, Churchill Livingstone (2000), ISBN: 044306240 4. J Osteopath Med. 2001;4(1):40-1

10. Straus SE, Glasziou P, Richardson WS, Haynes RB. Evidence-based medicine: how to practice and teach EBM. Philadelphia: Elsevier; 2019.

11. Feldbaum H, Lee K. Public health and security. In: Ingram A, editor. Health, foreign policy \& security: towards a conceptual framework for research and policy. UK Global Health Programme Working Paper No. 2. London: The Nuffield Trust; 2004. p. 19-28.

12. Aldis W. Health security as a public health concept: a critical analysis. Health Policy Plan. 2008;23(6):369-75.

13. Rushton S. Global health security: security for whom? Security from what? Political Studies. 2011;59(4):779-96.

14. Rushton S, Youde J, editors. Routledge handbook of global health security. London: Routledge; 2015.

15. Weir L. Inventing global health security, 1994-2005. In: Rushton S, Youde J, editors. Routledge handbook of global health security. London: Routledge; 2015. p. 18-31.

16. Eckmanns T, Füller H, Roberts SL. Digital epidemiology and global health security; an interdisciplinary conversation. Life Sci Soc Policy. 2019;15:2. doi: 10.1186/s40504-019-0091-8.

17. Russell R, Reid A, Borgers G, Wassink H, Grove A, Niebuhr DW, et al. A NATO guide for assessing deployability for military personnel with chronic medical conditions: medical fitness for expeditionary missions, Task Group 174, Human Factors, and Medicine Panel. Mil Med. 2014;179(12):1404-11.

18. Allied Joint Publication. NATO standard: AJP-01(E)(1) [Internet]. Brussels: NATO; 2017 [cited 2020 Mar 28]. Available from: https:// assets.publishing.service.gov.uk/government/uploads/system/uploads/ attachment_data/file/905877/20200728-doctrine_nato_allied_joint_doctrine ajp 01.pdf.

19. Mann-Salinas E. Evaluation of Role 2 (R2) medical resources in the Afghanistan combat theater: past, present and future [Internet]. Tacoma:
The Geneva Foundation; 2016 [cited 2020 Mar 28]. Available from: https://apps.dtic.mil/sti/pdfs/AD1033398.pdf.

20. Frantzen H. NATO and Peace Support Operations, 1991-1999: policies and doctrines. London: Frank Cass; 2005.

21. Borden Institute. Emergency war surgery. Fourth United States revision. Washington, DC: Borden Institute; 2013.

22. Zielinski M. Military trauma. In: Papadakos PJ, Gestring ML, editors. Encyclopedia of trauma care. Heidelberg: Springer; 2015. p. 413-4.

23. NATO. Collective defence - Article 5 [Internet]. NATO [updated 2019 Nov 25; cited 2020 Mar 28]. Available from: https://www.nato.int/cps/ en/natohq/topics_110496.htm.

24. Shea J. NATO's Warsaw Summit: re-establishing deterrence, projecting stability. In: Kammel A, Zyla B, editors. Peacebuilding at home: NATO and its 'new' Member States after Crimea. Baden-Baden: Nomos Verlagsgesellschaft; 2018. p. 209-22.

25. Shalamanov V. Cyber defense in NATO's perspective: counter-terrorism context in SEE. In: Minchev Z, Bogdanoski M, editors. Countering terrorist activities in cyberspace. Amsterdam: IOS Press; 2018. p. 12-24.

26. U.S. Army Peacekeeping and Stability Operations Institute; Marr S. Stability in multi-domain battle. Carlisle: PKSOI; 2018.

27. Multi-Domain Battle: evolution of combined arms for the 21 st century, 2025-2040 [Internet]. U.S. Army Training and Doctrine Command; 2017 [cited 2020 Mar 28]. Available from: https://www.tradoc.army.mil/ Portals/14/Documents/MDB_Evolutionfor21st\%20(1).pdf.

28. Perkins W, Olivieri A. On multi-domain operations: is NATO today sufficiently 'Joint' to begin discussions regarding multi-domain command and control? JAPCC. 2018;(26):16-23.

29. Allen MA, Fordham BO. From Melos to Baghdad: explaining resistance to militarized challenges from more powerful states. Int Stud Q. 2011;55(4):1025-45.

30. Arreguín-Toft I. How the weak win wars: a theory of asymmetric conflict. Cambridge Studies in International Relations, 99. New York: Cambridge University Press; 2005.

31. Wither JK. Making sense of hybrid warfare. Connections. 2016;15(2):7387.

32. Johnson R. Hybrid war and its countermeasures: a critique of the literature. Small Wars Insurgencies. 2018;29(1):141-63.

33. Nemeth WJ. Future war and Chechnya: a case for hybrid warfare. Monterey: Naval Postgraduate School; 2002.

34. Andresson J, Tardy T. Hybrid: what's in a name? [Internet]. Paris: EUISS; 2015 [cited 2020 Mar 28]. Available from: https://www.iss.europa.eu/ content/hybrid-what's-name.

35. Chivvis CS. Understanding russian "hybrid warfare": and what can be done about it. Santa Monica: RAND Corporation; 2017

36. Van Puyvelde D. Hybrid war - does it even exist? [Internet]. NATO Review; 2015 [cited 2020 Mar 28]. Available from: https://www.nato. int/docu/review/articles/2015/05/07/hybrid-war-does-it-even-exist/index. html.

37. Woolley T, Badloe J, Bohonek M, Taylor AL, Erik Heier H, Doughty H. NATO Blood Panel perspectives on changes to military prehospital resuscitation policies: current and future practice. Transfusion. 2016;56 Suppl 2:S217-23.

38. Rappold JF, Spinella PC. Editors' preface to the THOR 2018 supplement. J Trauma Acute Care Surg. 2018 Jun;84(6S Suppl 1):S1-S2.

39. Yazer MH, Cap AP, Spinella PC. Raising the standards on whole blood. J Trauma Acute Care Surg. 2018 Jun;84(6S Suppl 1):S14-S17.

40. Heier HE, Badloe J, Bohonek M, Cap A, Doughty H, Korsak J, et al. Use of tranexamic acid in bleeding combat casualties. Mil Med. 2015;180(8):844-6.

41. Joint Trauma System. Clinical Practice Guidelines (CPGs) [Internet]. JTS [updated 2020 Mar 11; cited 2020 Mar 28]. Available from: https:// jts.amedd.army.mil/index.cfm/PI_CPGs/cpgs. 